\title{
SCHOOL INSTRUCTION IN MATTERS OF SEX.
}

\author{
W. S. FOSTER, \\ Cornell Cuiversity.
}

This paper is not intended as a contribution of new facts to the subject it discusses. Facts may be found in abundance -confusing abundance-in the literature of sex-hygiene, which has grown to such proportions of late years that a mere list of references covers several pages. But as is evidenced by this very productirity, there is at present a movement to bring the sex-skeleton out of the closet and into the light, and to see what can be done to make it a respectable living factor, instead of leaving it to make trouble for the inmates of the house. It seems worth while to attempt a selection and concatenation of the facts given us by the workers in the various fields, medicine, hygiene, education, psychology, ethics, and so on, with the airn of arriving at conclusions which help to solve the specific problems of the teacher and school administrator.

The full realization of the need of some means of securing proper attitudes and better conduct in the sexual realm has come comparatively recently. Probably the most strenuous influence in the movement for amelioration has been the knowledge of the wide and ever-increasing spread of venereal diseases, together with new knowledge of their subtle nature and terrible and far-reaching effects. Physicians declare that 60 per cent. of men become infected at some time during life; that besides the direct misery that they entail, these diseases are by far the most potent factors in the causation of deaf-mutism, idiocy, insanity, paralysis and locomotor ataxia; that much of the ill-health of women, 80 per cent. of the inflammatory diseases of women, are due to gonococcus infection alone; that 50 per cent. of ophthalmia and 20 to 25 per cent. of all blindness is due to the same cause; that 50 per cent. of infected women are rendered sterile by it; that 60 to 80 per cent. of children infected with syphilis die at birth or come into the (440) 
world with the mark of death upon them, while the rest are subject to degenerative changes which may be passed on to the third generation. And in common with these diseases, sexual disorders, such as phobias, obsessions, hysteria, masturbation and sexual perversions, are so common and so uncertain of cure that we are absolutely driven to the far more important problem-that of prevention. ${ }^{1}$

So much for the diseases and abnormalities. These are not the only dangers. Of late what is called the dynamic school of psychologists has shown us how in a litherto scarcely conceivable way and to a hitherto unthought-of degree, healthy mental life depends upon proper enlightenment and training in sexual matters, especially in very early life. We cannot here detail their methods and conclusions. The facts and their cducational bearings have been presented in this JoukNal in an article by Jones (7), entitled "Psycho-Analysis and Education." One short quotation will show the nature of his conclusions. "Experience teaches that when later interests, desires and ambitions are traced to their origin, far more than are commonly thought are found to arise in the psycho-sexual instincts. * * * This really follows from the view that mental life is evolved in the individual from the inborn instincts; for 'of all these the sexual ones are the most fundamentally important, certainly from the point of view of mind; it is the manifold richness of his sexual life that biologically most distinguishes man from the lower animals." "2

Physicians and psychologists, however, are not the only ones who are beginning to realize the need of a change in our methods of preparing the young for modern life. The criminologist, the social worker, the minister and the teacher realize it also. The common man, as education becomes more general and more generally advanced, can see that life conditions are changing, and that the old insistence on silence about sex topics and the old teaching that all sexual feeling is low and bad must soon be superseded. It has become apparent, even on common-sense grounds, that the young must be impressed

${ }^{1}$ A. S. S. M. P., Leaflet (1), reprinted from Morrow (11). See also Henderson (6), pt. 1, A. S. S. M. P. (1), Pam. No. 3, and Ellís (4), pp. 319-331.

Jones (T), p. 500. See also references there given. Ellis (4) and Hall (5) express somewhat similar ideas. 
more and more with their responsibilities, and prepared more definitely for meeting actual conditions.

Will instruction prevent? Instruction here is no move a cure-all than it is in other fields:-but that is fundamental; that it is the best and most powerful means as well as one of the most neglected ones-on this, the authorities are agreed and emphatic. They point out that it is not a question of silence versus teaching, but of good versus bad instruction. The child is bound to get answers to his questions from some source. Denying the need of instruction is like holding it unnecessary to furnish pure water to drink when there are plenty of puddles in the street. 'The real reason for maintaining' silence is a false modesty or foolish sentiment, together with an ignorance of the importance and necessity of teaching, rather than a reason based on theoretical objections to enlightenment. One conld quote lundreds of passages. A few will suffice. "While there are other causes which contribute to the spread of these [venereal] diseases, the basic cause is ignorance." "I am now convinced that the uplifting of the morality of our people lies, above all and everything else, in educating the children, rationally and morally. I believe that more evil has been done by the squeamishness of parents who are afraid to instruct their children in the vital facts of life than by all the other agencies of vice put together. * * * Thousands of men have asked me why they were not taught the dangers of vice in their youth, and I have had no repls to make to them." "At best, law, police and government can do little more than affect the external conduct. * * We must look to some influence far deeper and more pervasive for the ultimate self-regulation of life in accordance with the laws of social welfare and the noblest life. This influence is education, and we turn, therefore, from the medical profession and the statesman to that profession which deals with the character, the will and the moral nature in the most direct and persuasive way ; we make our appeal to the school teachers and parents."

A. S. S. M. P., Leatlet (1).

'Bishop of Loudon (2).

'Henderson (6), pt. 1, p. 74. 
"No doubt is any longer possible as to the absolute necessity of taking deliberate and active part in sexual initiation."

Even if the dangers we have mentioned did not exist, instruetion should still be maintained. To eliminate the unnecessary worry and self-approach of the uninstructed adolescent, to overcome the deceit and hypocrisy which he is forced to maintain toward his parents and others who insist on silence on sex matters, to set right the false ideas and ideals which this attitude on the part of others causes him to develop, we must see that the truth is taught in a proper and natural may.' In conclusion, we see no good reasons why instruction should not be given, and with the foregoing in mind we can certainly maintain the real and pressing need for giving it.

We come now to the problem of the time for instruction, and to the question as to who should give it. The psycho-analytic investigations above referred to have shown that real desires for knowledge of sexual matters arise in children very much earlier than we are accustomed to think, and that if true expla. nations are not given, false ones are sure to be heard or invented, probably with serious results. ${ }^{8}$ It is to be pointed out that to the young child sex matters are not different from other unatters till the attitude of the teacher makes them so; that a proper attitude toward sex can be developed, provided the real facts are frankly and simply told. Later, such an attempt will probably have to overcome acquired ideas and feelings of shame and embarrassment. ${ }^{.}$It should be a rule to answer questions and to satisfy curjosity as soon as it arises, not making sexual enlightenment an isolated or specially emphasized, but a natural and integral part of general enlightenment. ${ }^{10}$ Certainly all authorities agree that a good ground work, a satisfaction of all insistent curiosity, should be secured before

- IElHs (4), p. 43.

iOn adolescent worrs and false idens, see Hall (.5), 1, pl). 457-4GS: on distrusts, see Lyttleton (10), pp. 16-23; Jones (T), pp. 510-512.

sWe are just beginning to realize the chnracter and complexity of sexual interests in early life, and to catch lints at thelr growth and transformation into later trends. Seemingly small things in the way of information, circumstance or training may be of profound significance for directing these early tendencies. either towards the establishment of the normal or towards raisiag one or more of them to the rank of a perversion.

'Schmitt (15), p. 235.

10.Cllis (4), 1p. 48-49; Lyttleton (10), pn. 69-70, 79-81. 
the child goes to school or otherwise becomes open to sources of misinformation and danger. If information has not been given by this time, the teacher is no longer so free to speak, nor so influential, so that the words are either left unsaid or come with little force. ${ }^{11}$

There has been much discussion on the question of preversus post- pubertal sex instruction. The answer must of necessity be: "Both." Sexual enlightenment, like any other" enlightenment, should be continuous, progressive and suited to the development and needs of the learner. The young child requires control and simple facts; the boy at school has needs and interests at quite a different level. The marking off of a specific time for a general and complete (?) instruction is certainly not to be recommended.

Since, then, instruction should begin thus early, and since the mother is the natural teacher in early years, as well as the one most likely to be influential, there can be no question but that she should begin the instruction. ${ }^{12}$ But the mother's teachings, of which the aesthetic elements are more important than the informative, must always be supplemented by that of the school. At the present day mothers are generally ignorant of the biological and physiological facts that should be common knowledge. Many not actually ignorant are unwilling to teach. If the children of this and the next generation are not to take a similar dangerous attitude, we must train them in the school to the right ways of thinking. ${ }^{18}$ Leaving the subject of reproduction out of the textbooks and shunning all references to matters involving sex in biology or history or literature, or what not, is completely contrary to the spirit of the whole movement toward right thinking. The teacher, who is with the child for so much of the time, who has such a powerful influence and such magnificent chances for imparting proper knowledge and ideals, certainly cannot escape the responsibility of treating sex matters. ${ }^{14}$

It would be foreign to our purpose to detail the part in this instruction which may be taken by the doctor. Suffice it to say

${ }^{11}$ A. S. S. M. P. (1), Pam. No. 2, pp. 10-12.

${ }^{25}$ Ellis (4), pp. 48-49.

${ }^{23}$ Jones (7), p. 515.

"Henderson (6), pt. 11, pp. $27 \mathrm{ff}$. 
that his training and the confidential relations which he sustains to the patient make him a natural, direct and influential teacher. His words in a personal talk or in a lecture will be listened to by the older boys, who would be more apt to disregard the same admonitions from other sources. There is a real chance for the minister or Sunday-school teacher also, provided he really has the child's confidence and can talk plainly and not too 'preachily,' but unfortunately most religious teachers cannot do so, and do not consider that such subjects lie within their province. ${ }^{15}$

We now come to the fundamental questions of instruction itself, namely, what should be the content of instruction, and what means are most suitable for the presentation of this content? We have already given some indication of the answer when we insisted that different content should be given at different stages of development of the learner. We may, for convenience, treat of three periods : the home and kindergarten stage, the pre-pubertal stage and the adolescent stage.

The training of the first stage, as we have suggested, belongs chiefly to the mother. The kindergarten or grade teacher is called upon so urgently chiefly because there has been total neglect or actually bad home training, for which she must make up as best she may. The sort of training required is admirably set forth by Ellis (4), and there are a number of little books which he refers to, as well as some more recent ones, which present the subject simply and briefly. But we doubt that most mothers need to read these books in order to know what to say. Ellis remarks: "I may add that while it would usually he helpful to a mother to be acquainted with a few of the booklets I have mentioned, she would do well in actually talking to her children, to rels mainly on her own knowledge and inspiration." The training in this period should include the formation of habits of cleanliness and care of the bods, the implanting of the feeling of its sacredness, the imparting of simple facts as to the origin of babies and as to the functions of the reproductive organs. The child should, of course, be

\footnotetext{
${ }^{26}$ Ellis (4), pp. $48-53$ and references there; Lyttleton (10), pp. 78-87; Henderson (6), pt. II, pp. 28-30; Lowry (8 and 9).

${ }^{15} \mathrm{On}$ the place of religion in this regard, see Hall (5), I, pp. $463 \mathrm{ff}$; Lyttleton (10), note, p. 97 .
} 
warned not to discuss these matters with outsiders any more than he is to discuss any family affairs with them. He should be made to feel free to ask mother any questions he likes, and should be assured of a correct answer. The matter must be treated with absolute frankness and honesty if one cares for the best results. Opportunities for talking of sex matters in a natural contest should not be neglected. Many recommend using the facts of reproduction in flowers and animals as ir proper introduction to the essential facts of human reproduction. While such facts are extremely valuable in proper hands for the illustration of certain points or phases of the matter, it seems not at all necessary that the mother should know them in order to do good. Far too often such illustrations serve merely as hints at the truth, as excuses for not being frank, and leave the child with the impression that the subject is bein. skimmed over because it isn't nice.

And with regard to training or instruction, let us here add that by these terms we do not mean the mere giving of information. It is important that besides knowledge-even more than knowledge, perhaps - there shall be imparted right feelings, right attitudes and points of view, right habits and right ideals. As a recent writer" puts it, we need a "consecration of the affections" rather than a purely factual sex-liygiene. He insists that the teaching, "If you're bad, you'll suffer," isn't always true. Even if it were, it would lead to a pretty cheap sort of morality. It will not, moreover, accomplish results. Their superior knowledge of the effects of morphine does not prevent doctors from being the worst offenders in the drug habit. We hold opinions and regulate conduct as we do, far more because the people we like think and act in that way, than because we reason from facts or consider results. The personality of the instructor, therefore, his attitude toward his subject and toward life, undoubtedly play as important a part in results as do the facts he teaches. One experienced teacher says: "The real answer to the question of the two methods [the informatory and the personal] is that they both ought to be combined, and that by far the greater stress should be laid on the personal appeal. * * * Granted that a father's

${ }^{17}$ Cabot (3). 
iesson about plant life is immeasurably better than the unclean hints gathered from other sources, which is all that most ehildren have to be satisfied with at present, still such a lesson would be grievously defective in its power of appeal, because it would leave out of account the two greatest influences which a child is capable of feeling-religious reverence and his love for his mother; the first not necessarily, but very probably. It may be reasonably asserted that the wholesome impressions of childhood, which consciously and vividly last through life, are those made by onc or both of these influences. ${ }^{18}$

The instruction in the pre-pubertal period should be an enlargement on the subjects treated in the first stage, together with specific preparation for the changes of puberty. There should be an explanation of sexual experiences (nocturnal emissions, menstruation, etc.) and their hygiene. ${ }^{10}$ There should be specific warnings against masturbation and bad company, with explanations of the why of present and ideal attitudes and conduct. The child should be made to feel free to ask questions of, and listen to some wise and sympathetic older person with regard to the psychology, hygiene and ethics of sex. This much of the instruction again would be best if given by the parents, for naturally they could be more personal and confidential and intimate than any others. Rarely only, it seems to us, could the teacher do so well. His instruction will, in most cases, be more indirect and objective and informative, resulting chiefly from his attitude toward the sex matters involved in his subject, and from the facts given in the biological courses. Personal talks on sex topics by him ought to be optional and the occasions dictated by common sense, just as are personal talks on religion or choice of a profession.

Much has been said for the courses in the biological sciences for teaching these personal lessons, as well as the more purely informative facts of reproduction which lie strictly within their province. Courses have been given with these things in mind, and the reports are decidedly favorable. ${ }^{20}$

There are a number of reasons, however, why it seems

\footnotetext{
${ }^{25}$ Lyttleton (10), p. 77. Cabot (3), p. 119, goes so far as to maintain that the "contagion of personality" is "what keeps any of us straight."

${ }^{19}$ See Hall (5), 8; Ellis (4), esp. p. 64 .

${ }^{2}$ Henderson (6), pt. II, p. 26.
} 
hardly likely that such courses alone will be adequate. For the most part, they are given in the high school, and hence come too late to be of greatest benefit. The content which strictly belongs to them is not sufficient. The teacher must usually be objective, and cannot well bring in either the more personal facts or their applications without forcing. Most teachers are not prepared to give such courses. And lastly, the subjects themselves, as they stand, are not suited to teach all the lessons we want. Henderson says: "Nature study is a good introduction to sexual pedagogy, but it is not adequate and complete. This is because man is not only an animal, a nature object, but vastly more; he is a person, a moral being, selfdirected, and also under social law and spiritual obligations. * * The youth needs to know the historical origin of social inhibitions, shame, modesty, marriage, etc., and their reasons in physiology, economics and the necessity of building up character by self-control.,"21 Cabot also objects to regarding such teaching as altogether good or adequate. "There is nothing about Nature that should make us look up to her as a source of good example in this field. The behavior of most of the insects and animals that we see about us is far from being a model for human beings in the relations of sex. All that we can get from nature here is an awful warning as to the depths to which we might conceivably fall. The promiscuous and temporary character of the relations observable among most of the animals which we see about us in civilized life is precisely what we wish to avoid in the relations of men and women." It seems necessary in general, therefore, that the courses in biology should be at least supplemented by more personal and direct means. There is much to be said in favor of special lectures by the biology teacher, a doctor or some other competent person. Considering actual present conditions, the usual custorn of segregation of the sexes and optional attendance is probably wise. ${ }^{22}$

\footnotetext{
${ }^{20}$ Phelps (12) ; Putnam (13 and 14). Henderson (6). pt. II. p. 78 ff., and Talmey (16), pp. 71 ff., outline courses. See also A. S. S. M. P., Pam. No. 2, pp. 6-8.

${ }^{21}$ a Cabot (3), p. 118.

${ }^{22}$ Zenner (17) gives an account of such lectures, but those he gives seem hardly complete and detailed enough, nor entirely suited to his auditors.
} 
There is still another means to be mentioned which, in the hands of an earnest administrator, would seem to have great possibilities, since, if successful, it goes well to the root of the matter. We refer to parents' meetings, at which the principal, a doctor, a minister or some other earnest and well-educated man can show the parents the need and possibility of giving their children instruction in sex in the home and the desirability of permitting such instruction by classes and lectures in the school. It assuredly seems to us that this sort of education of the parents can go a long way toward removing the ban on the consideration of sex.

Before the child leaves school there should also be given the instruction we have spoken of as coming in the adolescent stage. No child should be left entirely ignorant of the fundamental meaning and duties of marriage, of the facts of prostitution and venereal diseases, and of their results. Young people should be taught how to regard these matters rationally. Perhaps by this time the child will be far enough developed so that a means not hitherto spoken of, namely, books, may be used in connection with other means. ${ }^{23}$ We are inclined to think that the use of books in the earlier stages is not of great udvantage. They do not give the personal touch that we believe is so fundamental, but oftentimes serve rather as an excuse for omitting the personal talk. Most books are one-sided; practically all of them are incomplete in some respect. Many exaggerate and attempt to scare the child into virtue. On the contrary, the child should be told the real facts and be sure of sympathy. ${ }^{24}$ Quack books and quack doctors are blamed for much of the worry which the uninstructed adolescent undergroes. 20

Besides instruction in a narrow sense, we may mention various other means which serve more indirectly for the proper regulation of the sexual life. Interest and participation in athletics and social affairs, in literature, poetry, language, religion, and so on, the filling of the youth's mind with a lifework and the directing of his energies toward it, all help

\footnotetext{
2Morrow (11), Ellis (4), and Lyttleton (10) are good.

${ }^{2}$ Lyttleton (10), pp. 92-97.

${ }^{\mathrm{s}}$ Hall (5), I, pp. 463-464.
} 
to "long-circuit" his instinctive tendencies (Hall), "sublimate" his desires (Jones), "transform his vital energy" (Cabot).

\section{REFERENCRS.}

1. American Society of Sanitary and Moral Proplurluxis: Lenflet and six pampliets.

2. Tisuor or Loxuon, Iadies' Home Journal, May, 100 S.

3. R. C. Canot. Consecration of the Affections (Often Misnamed SexHygicne). Proceedings of the Fifth Congress of the Auerican School Hygiene Association, III, 1911, p. 114.

4. If. ELLIS. S's and Society, the sixth rolume of a series entitled Studies in the Psrchology of Sex, 1010.

5. G. S. Halt. Adolescence, 2 vol., 1904.

6. C. R. Hexperson. Education with Refercnce to Sex. Eighth Year Book, National Societs for the Scientific Study of Fducation, 2 parts, 1009.

T. E. Joxes. Psycho-dualysis and Educatom Journal of Educational Psychologx, I. No. 9, 1910, p. $49 \%$.

8. F. B. Lowny. Confidences. 1910.

9. 13. B. Lown'. T'ruthe. 1011

10. F. LrTrterox. Training the Yonty in the Lates of Sex. 1910.

11. P. A. Monnow. Social Diseases and Marriage. 1904.

12. J. Pielps. Biologic T'cuching of Sex. Transactions of the American Association tor the Studs and Prevention of Infant Mortality. Baltimore, 1910, p. 291.

18. If. C. Putnay. Iractucability of Instruction in the Psychology and Uygiene of Sex as Demonstrated in Several Public Schools. Boston Medical and Surgical Jourual, 1907.

14. H. C. PutNas. The Teaching of IIygiene through Domestic Science and through Nature study. leport of Committee to Iuvestigate the Teaching of Hygieve through Domestic Science and through Nature Study, American Acadeny of Medicine.

15. C. Scruntr. The Teaching of the Facts of Sex in the Public School. Pedagogicul Seminary, XXIV, No. 2. 1910, p. 229.

16. 13. Tarney, Girncsis. 1910.

17. 1'. Zarver. Educotion in Sexual P'hysiology and Hygiene. 1910. 